\title{
Connecting primate gesture to the evolutionary roots of language: A systematic review
}

\author{
Evelina D. Rodrigues $^{1}$ | António J. Santos ${ }^{1}$ | Flávia Veppo ${ }^{2}$ | Joana Pereira ${ }^{3}$ | \\ Catherine Hobaiter ${ }^{4}$
}

${ }^{1}$ William James Center for Research, ISPA-Instituto Universitário, Lisbon, Portugal

${ }^{2}$ Department of Applied Psychology, School of Psychology, University of Minho, Braga,

Portugal

${ }^{3}$ Centre for Ecology, Evolution and Environmental Changes, Faculdade de Ciências, Universidade de Lisboa, Lisboa, Portugal

${ }^{4}$ School of Psychology and Neuroscience, University of St Andrews, St Andrews, Scotland, UK

\section{Correspondence}

Evelina D. Rodrigues, William James Center for Research, ISPA-Instituto Universitário, Rua Jardim do Tabaco, no. 34, 1149-041 Lisboa, Portugal.

Email: erodrigues@ispa.pt

\section{Funding information}

Portuguese Foundation for Science and Technology, Grant/Award Number: SFRH/ BD/138406/2018

\begin{abstract}
Comparative psychology provides important contributions to our understanding of the origins of human language. The presence of common features in human and nonhuman primate communication can be used to suggest the evolutionary trajectories of potential precursors to language. However, to do so effectively, our findings must be comparable across diverse species. This systematic review describes the current landscape of data available from studies of gestural communication in human and nonhuman primates that make an explicit connection to language evolution. We found a similar number of studies on human and nonhuman primates, but that very few studies included data from more than one species. As a result, evolutionary inferences remain restricted to comparison across studies. We identify areas of focus, bias, and apparent gaps within the field. Different domains have been studied in human and nonhuman primates, with relatively few nonhuman primate studies of ontogeny and relatively few human studies of gesture form. Diversity in focus, methods, and socio-ecological context fill important gaps and provide nuanced understanding, but only where the source of any difference between studies is transparent. Many studies provide some definition for their use of gesture; but definitions of gesture, and in particular, criteria for intentional use, are absent in the majority of human studies. We find systematic differences between human and nonhuman primate studies in the research scope, incorporation of other modalities, research setting, and study design. We highlight eight particular areas in a call to action through which we can strengthen our ability to investigate gestural communication's contribution within the evolutionary roots of human language.
\end{abstract}

\section{KEYWORDS}

domains, gestures, humans, language evolution, nonhuman primates

\section{1 | INTRODUCTION}

Human language is a rich system of communication often argued to be qualitatively distinct from other animal species' communication (Christiansen \& Chater, 2015; Hauser et al., 2002; Pinker \& Jackendoff, 2005). The thousands of modern human languages are distinct in their expression, so much so that being a proficient language user in one language allows access to, at best, just a handful of others. Despite this, across the spectrum of modern human languages, each one contains a similar capacity for language-like communication. How and when language emerged remains under significant debate (e.g., Bolhuis et al., 2014; Corballis, 2002; Richerson \& Boyd, 2010); but it was likely built on precursors, some of which may be detected in the communication of our modern primate relatives. 
The availability of fossil evidence to resolve these debates is limited (Hsieh \& Plotnick, 2020; although cf. Arensburg et al., 1989; MacLarnon \& Hewitt, 1999); and comparative studies of modern primate species' communication provide valuable insight. The presence and absence of features within human and nonhuman primate communication suggest potential precursors to modern systems of communication, and the pattern of presence across primate phylogeny can offer a potential timescale for their emergence. Comparisons within and across species typically rely on comparison across studies. Diversity in study methodology-from study species to socioecological context and more-is critical to properly exploring the full landscape of primate gestural expression. However, such diversity makes subsequent comparison across studies challenging, particularly where definitions and conceptual boundaries are opaque. In this systematic review, we investigate those studies of spontaneous gestural communication in human and nonhuman primates that articulate an explicit connection between gesture and the evolutionary origins of modern human language. We incorporate a first use of Bourjade et al.'s conceptual framework for systematic comparison of gesture definitions (Bourjade et al., 2020) and investigate variation in different domains of research, in the study scope, in the inclusion of other signal sources (e.g., vocalizations), in the research setting, and in study design. We aim to provide an up-to-date description of the field, highlighting both what is understood and the areas in need of further research.

Language can be expressed in many forms, including spoken and signed: it is not the signal modality or channel of communication that defines human language so much as the way in which it is used. Many systems of communication across species encode sophisticated information, but nonhuman communication is typically broadcast irrespective of a recipient's attention, interest, or even presence (Rendall et al., 2009). Detecting language-like intentional communication is challenging because it depends not on the observable physical form of the signal but on the cognitive intention of the signaller. Imagine driving along a road and hearing another driver honking their horn as they approach you; there is no fixed information encoded in that signal. Unlike the acoustic structure of a monkey alarm-call (e.g., Seyfarth \& Cheney, 2003a, 2003b), the uses of a car horn can mean very different things depending on what the signaller intends them to mean.

Intentional use, while a fundamental property of human language, remains apparently rare in communication of other species, including in many primate vocalizations (Rendall et al., 2009; Seyfarth \& Cheney, 2003a, 2003b, although see Schel et al., 2013; Townsend et al., 2017). There is an exception: Evidence for flexible intentional use is abundant in nonhuman ape (hereafter ape) gesture (Leavens, Russell, et al., 2005; Plooij, 1978; Tomasello et al., 1985), driving interest in the evolutionary connections between ape gesture and human language, and "gesture-first" hypotheses of language evolution (Corballis, 2002; Hewes et al., 1973; Rizzolatti \& Arbib, 1998). More recent articulations recognize that language-like all animal systems of communication-is multimodal, and likely derived from multimodal systems (Gillespie-Lynch et al., 2014; Leavens, Russell, et al., 2010; Prieur et al., 2020; Taglialatela et al., 2011) but may have included a transition in the role of the different modalities, for example, a shift in the vocal modality from supporting to carrying of information (e.g., Fröhlich et al., 2019).

Comparative studies seeking to draw specific comparisons between primate gesture and human language have been used to explore different aspects of primate species' gesturing including the physical form (as compared with linguistic lexicons; e.g., Brentari et al., 2012) and meaning (as compared with language-like semantics) of gestural signals (often through the study of message and context; e.g., Graham et al., 2018). The structure of gestural communication (in sequences of gestures; as compared with combinatorial structure and syntax in language; e.g., Hall et al., 2015), and the integration of gestural signals with other signal types, such as vocalizations and facial expression (combination of sources; e.g., Hobaiter \& Byrne, 2017). From the perspective of the signaller and recipient, researchers have investigated how gesture develops behaviorally during ontogeny (e.g., Salo et al., 2018) and neurologically (neural processes; e.g., Biau et al., 2016), and similarities between how gesture and language are deployed (in brain or limb laterality; e.g., Meguerditchian et al., 2011).

One complication within gestural research is the fact that researchers have no direct access to cognitive states (of either nonhuman or human subjects), and instead employ visible behavioral criteria to infer signaller intentions. These behavioral criteria were first developed in studies of pre-verbal human infants' ability to capture the attention of others and manipulate their behavior (Bates et al., 1975, 1979). Today, criteria include behavior such as whether the signaller shows sensitivity to the attentional state or composition of the audience, whether they pause (wait) for a response, and if they persist or elaborate when the recipient fails to respond (Leavens, Russell, et al., 2005; Liebal et al., 2004; Tomasello \& Call, 1997). However, as the study of nonhuman primate gesture developed there has been variation in how these criteria have been operationalized and employed (Bourjade et al., 2020; Fröhlich et al., 2018; Leavens, Russell, et al., 2005).

Our ability to reliably detect patterns of similarity and distinction across modern primate species' communication is central to our ability to make inferences about the evolutionary trajectory of language. Variation in research settings, methods, or contexts can represent strength, allowing for robust exploration of a particular finding. However, for this to be the case, it is key that diverse methods are transparent about sources of variation (Bourjade et al., 2020; Fröhlich \& Hobaiter, 2018). Characteristics of our study sample such as social background, responsiveness, or prior experience impact the generalizability of our findings (cf. STRANGE framework, Webster \& Rutz, 2020), and the overrepresentation of particular species or populations distort our ability to make phylogenetic comparisons (e.g., WEIRD-Western, Educated, Industrialized, Rich, and Democratic-humans, or BIZARRE-Barren Institutional Zoo And other Rare Rearing Environment-chimpanzees; Henrich et al., 2010; Leavens, Bard, et al., 2010). Previous studies have highlighted how systematic species-differences in individual 
history, tasks, and testing environments are confounded with apparent species-differences in communicative or other socio-cognitive abilities, such as their ability to follow gaze or produce pointing (Boesch, 2020; Leavens et al., 2019). Differences in methodology and context of the study appear particularly profound when comparing human and nonhuman primate behavior (Bard \& Leavens, 2014; Leavens et al., 2019). Some of these differences may involve, for example, comparisons of institutionalized adult apes with noninstitutionalized human children, or apes in caged environments with free-roaming human children (Bard \& Hopkins, 2018; Boesch, 2020; Leavens et al., 2019). In some cases, variation in our understanding across species is limited by what is both technologically feasible and/ or ethical in nonhuman species, for example, the exploration of neural processes inside of living brains (cf. Meguerditchian et al., 2010; Rizzolatti \& Arbib, 1998).

To explore meaningful patterns of similarity and distinction between human language and nonhuman gestural communication, we need to address apparent discrepancies in research approach and understanding. A crucial first step in this process is to better understand where any differences currently lie. A systematic assessment of the field allows us to better gauge the impact of any biases on our ability to develop clear hypotheses about the evolutionary trajectory of gesture and language. Bourjade and colleagues recently (2020) developed a framework to allow the systematic comparison of gestural definitions across primate studies-incorporating body parts, sensory modalities, social expression, and communicative and intentional properties. We include a first use of this tool, describing how primate species and study domains of gestural research vary in their concept of gesture, and then assessing how the species and study domains are differently represented in terms of study scope, the inclusion of additional sources such as vocalization or facial expression, and in research settings and study design. With this review, we aim to (1) identify both the areas of focus and apparent gaps within the field in studies that explore the connection between gestural communication and the evolution of human language, and (2) identify to what extent useful comparison can be made across human and nonhuman studies at the present time and make recommendations for the future.

\section{2 | METHODS}

In March 2020, we conducted a search of peer-reviewed articles and book chapters in two search engines: Web of Science and PsycINFO. We used the SPIDER framework (Cooke et al., 2013) as the search tool to define our question scope and organize and list terms by the main concepts in the search question (Table 1).

\subsection{Search}

We used the Phenomenon of Interest and the Evaluation categories from the SPIDER framework (Table 1) for our search string. We employed the largest time window allowed (1900-2019) and used both Web of Science and Psychlnfo databases. While our search window extended back to 1900 , more recent work is more thoroughly indexed in electronic databases, and as a result, our search procedure may have failed to detect some earlier studies. Literature within Web of Science is systematically structured literature from the 1950s and both Web of Science and Psychlnfo include books and other material within the Social Sciences and Humanities that are out of copyright. We did not apply search terms related to the sample (e.g., human, nonhuman, or even primates) at this stage, because research conducted on human (as compared with nonhuman) primates does not typically specify taxonomic terms to define the sample. Similarly, the type of study terms described in the design category (e.g., observational, experimental) is also often omitted in human work, so we removed this criterion in the first selection phase. Although no language restriction was applied at this stage, only studies with English abstracts or keywords were returned by the search because the search terms were in English. In PsychINFO, the search term "gestur*," AND "evolutio*" OR "origin*," AND "languag*" or "communicat*" was used as a filter in the title ( $\mathrm{TI})$, abstract (AB), or keyword (KW). In Web of Science, the same search terms were used as a topic (TS) filter (equivalent to title, abstract, and keywords in Psychlnfo). The final search string used in Web of Science was (TS = gestur* AND TS $=$ (languag* ${ }^{*}$ OR communicat ${ }^{*}$ ) AND TS $=$ (evolutio* OR origin*)).

\subsection{Inclusion and exclusion criteria}

We included publications in the review if they (a) included data from primates, (b) had gestures as the main focus, (c) make explicit the link between their study and language evolution; and (d) relied on spontaneous communication. We included both journal articles and book chapters. Whole books (as a single "unit") were not included because they typically include a range of differently structured studies, so considering them as their individual chapters was more compatible with the data extraction for journal articles. While all publications had to explore at least gestural signals, we also considered those employing a "multisource" approach (extracting the information on data from other sources, such as vocalizations, for analysis).

TABLE 1 Search Tool SPIDER as applied to the current review

\begin{tabular}{ll}
\hline Search categories & Potential search terms \\
\hline Sample & Human and Nonhuman primates \\
\hline Phenomenon of Interest & $\begin{array}{c}\text { Language Evolution and Origins of } \\
\text { Language }\end{array}$ \\
\hline Design & Observational and Experimental studies \\
\hline Evaluation & $\begin{array}{c}\text { Gestural research domains of } \\
\text { comparison }\end{array}$ \\
\hline Research Type & Empirical Articles and Book Chapters \\
\hline
\end{tabular}


We restricted our review of studies on primate gesture to publications that included an explicit reference to the evolution (or origin) of language (or communication). To assess the impact of this restriction on the literature returned, we ran the same search excluding this requirement.

To be considered "spontaneous" gestural communication, gestures must have been produced without explicit training. We excluded signed languages because they represent language in its full modern form and, like spoken languages, they are taught to some extent. In contrast, homesign often develops spontaneously in an environment in which one person does not have easy access to the language modality of others around them. Home-sign studies can provide a unique opportunity to investigate the emergence of a combinatorial linguistic system (Goldin-Meadow \& Yang, 2017). While home-sign becomes formalized over time, it can incorporate the use of a range of spontaneous gesticulation, gestures, pantomime, and symbols and we retained these studies in this review. Our primary exclusion criteria for the publications were (a) publications with abstract, or full text not available; (b) publications written in languages other than English; publications not focused on (c) primates, (d) neuro-typical subjects, (e) gestures, (f) spontaneous communication, (g) publications without empirical data (e.g., theoretical); and (h) not about language evolution. We checked publications according to these criteria in the order described above, and excluded a publication as soon as they failed to fulfill any criterion (although in practice there may have been further additional reasons for their exclusion).

\subsection{Selection of material}

Figure 1 shows the selection process of the articles through the flow diagram. Each manuscript was independently and randomly assessed by at least two researchers in the two main stages of material selection: abstract screening and full-text screening. When two people disagreed or both were unsure about its inclusion, we solicited a third opinion (abstract screening: 127 of 963 publications; full-text screening: 78 of 221 publications). We located 697 publications (692 articles and 5 book chapters) in Web of Science and 464 in PsychINFO (362 articles and 102 book chapters). We removed 198 duplicates, leaving 963 publications, including 862 articles and 101 book chapters (for a full list of all 963 publications see Supporting Information ESMS1, all data are also available in an open repository at https://github.com/Wild-Minds/GestureStudies_ SystematicReview); the oldest publication was published in 1975, and the most recent in 2019. Running the same searches but omitting the requirement for evolution/origin of language/communication from the string returned 6440 publications.

After abstract screening of the 963 publications, we removed a further 742 publications, leaving 221 publications for full-text screening. In the full-text screening phase, we excluded a further 58 publications because they did not fit the inclusion criteria (see detailed explanation in Figure 1). We excluded publications not focused on primates or focused on neuro-atypical subjects during the abstract screening phase; however, the language evolution criterion was only applied at the full-text screening phase. Our final data set included 163 publications (156 articles, 7 book chapters; for a full list of records see Supporting Information ESMS2).

\section{4 | Fields for data extraction}

Fields for data extraction and their categories (Table 2) were developed following systematic assessment of a pilot search of the literature by $\operatorname{EDR}$ ( $n=383$ studies) and were then discussed to

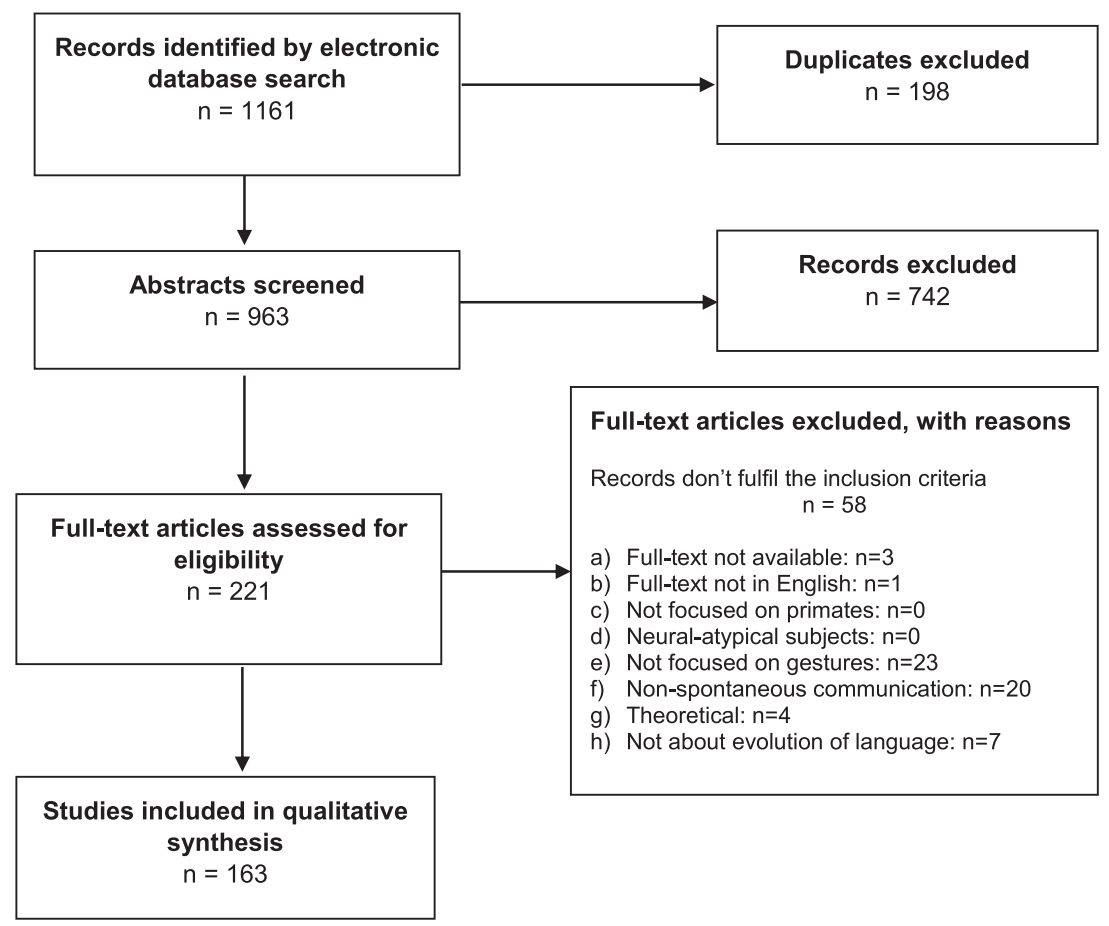

FIGURE 1 Flow diagram. Number of studies identified, included, and excluded and the reasons for exclusions through the different phases of the Systematic Review 
consensus between co-authors before being applied to the data set from the full systematic review. Please note that through Sections 2 and 3 of the manuscript, capitalized terms refer to these fields and categories of information extracted for analysis.

We recorded which Species of primate(s) was included in the study. Primate species were grouped into two categories: Human and Nonhuman primate categories, and within Nonhuman primates, we further distinguished the following groups: Great apes (Chimpanzees, Bonobos, Gorillas, Orang-utans), Small apes, Afro-Eurasian monkeys (also referred to as Old World), Monkeys of the Americas (also referred to as New World), and Strepsirrhines.

We described the proximity of the environment in which data were collected to the socio-ecological environment of evolutionary adaptation (EEA) for Nonhuman primate species. Given the extent of recent rapid anthropogenic change, this can be challenging to define for any modern species; however, for Nonhuman primates, we provide a cautious description of the environment as either SpeciesTypical (Wild, non-anthropogenically modified) or Species-Atypical (Man-made, anthropogenically modified). All captive Nonhuman primates were considered to be in Species-Atypical environments, wild primates were only considered to be in Species-Atypical environments where data collection occurred in anthropogenically modified habitats (e.g., in crop fields, human settlements).

We do not feel that any similar distinction can be made for modern Human populations, both because there is no solid evidence for what our human EEA looks like, and because all humans todaywhether urban city or hunter-gatherer communities-live in habitats that are substantially anthropogenically modified from that EEA. However, we provide an indication of local socioeconomic structure as being WEIRD (Henrich et al., 2010), Non-WEIRD industrial, or Small-scale nonindustrial. Please note that the category of subjects covered by "Rich" is a global one, and likely includes a range of economic groups in Western Industrialized Countries. These socioeconomic categories are not directly comparable to the Nonhuman primate ones of Species-Typical or Atypical.

We defined the Research Domain(s) explored, asking which area (s) of gestural communication were included in the study (e.g., form, structure, or ontogeny; see Table 3 for full list and definitions).

We asked whether there was an explicit Definition included for Gesture (see Table 2). For the publications which provide an explicit definition of gesture, we used the conceptual tool proposed by Bourjade et al. (2020) to analyze the requirements for a given behavior to be categorized as a gesture. The authors provided 22 criteria covering five main areas: the body parts used to gesture, the sensory modalities mobilized by the gesture, the characteristics of its social expression, and its communicative and intentional properties (see Supporting Information ESMS2 for full details).

Of those studies that provide an explicit definition of gesture, some include in this definition a requirement that they must fulfill certain intentionality criteria (captured by the "communicative and intentional properties" aspect of Bourjade et al.'s framework). However, other studies test for the presence or absence of these behavioral markers, and do not include them within the definition of gesture (if provided). To capture these cases, we further extracted whether or not there was a definition of or criteria for Intentional Communication, independently of their inclusion in any gesture definition. We also extracted information on the Body parts involved in gesturing even if they were not explicitly mentioned in the definition.

TABLE 2 Categories of each field extracted for analysis

\begin{tabular}{|c|c|}
\hline Field & Categories \\
\hline Species & $\begin{array}{l}\text { Humans } \\
\text { Nonhuman primates: Great apes (Chimpanzees, Bonobos, Gorillas, Orang-utans), Small apes, Afro-Eurasian } \\
\text { monkeys, Monkeys of the Americas, and Strepsirrhines }\end{array}$ \\
\hline Socio-ecology & $\begin{array}{l}\text { Nonhuman primates: Species-Typical (Wild non-anthropogenic); and Species-Atypical (Wild anthropogenic, } \\
\text { Captive anthropogenic); }\end{array}$ \\
\hline Socio-economy & Humans: WEIRD, Non-WEIRD industrialized, Small-scale non-industrialized \\
\hline Research domains of comparison & Combination of sources, Form, Laterality, Meaning, Neural processes, Ontogeny, and Structure \\
\hline Gesture definition & $\begin{array}{l}\text { Defined (transcription provided in Supporting Information ESMS2), not defined } \\
\text { Mechanical ineffectiveness: mentioned, not mentioned }\end{array}$ \\
\hline Intentional communication criteria & $\begin{array}{l}\text { Attention-getting behavior, Audience checking, Ceasing communication when goal is achieved, Change in } \\
\text { recipient behavior, Directed to recipient, Elaboration, Flexibility, Goal-directed, Initiating social interaction, } \\
\text { Mechanically ineffective, Persistence, Response waiting, Sensitivity to the attentional state of the recipient }\end{array}$ \\
\hline Body parts & Manual (hands, and upper limbs), Nonmanual (head, orofacial, body), Both (manual and nonmanual) \\
\hline Gestural scope & Broad, Narrow \\
\hline Multisource & Vocalizations, Facial expressions, Lexigrams, None \\
\hline Research setting & $\begin{array}{l}\text { Familiar (Human: Home, Day-care center; Nonhuman: Wild, Semi-Wild, Captivity); Unfamiliar } \\
\text { (Laboratory); Both }\end{array}$ \\
\hline Study Design & , Both \\
\hline
\end{tabular}


TABLE 3 Descriptions of the research domains of comparison

\begin{tabular}{|c|c|}
\hline Research domains & Description \\
\hline Combination of sources & $\begin{array}{l}\text { Coexistence of two different signal categories (gesture, vocalization, and/or facial expression). Includes studies focused } \\
\text { on the synchronization of the different sources }\end{array}$ \\
\hline Form & Physical form of the gesture(s). Includes studies that describe gestural repertoires \\
\hline Laterality & Predominance of one side of the body/brain involved in the execution of the communicative acts \\
\hline Meaning & $\begin{array}{l}\text { Used in the broad sense without requirement for intentional use. Includes all informational and/or semantic content of } \\
\text { gestures. Includes studies on iconicity, reference, and function }\end{array}$ \\
\hline Neural processes & Use of neuroimaging technology to study neural networks and their relation to communicative outputs \\
\hline Ontogeny & Development of communication and how it changes during the early stages of life \\
\hline Structure & Order and patterning of the communicative elements. Includes syntax \\
\hline
\end{tabular}

We did not include Body parts recorded as involved in non-gestural signals in this field, for example, orofacial body parts used in facial expressions. We marked a study as Multisource if it included information on Vocalizations, Facial expressions, and/or Lexigrams (arbitrary visual symbols representing words) used in addition to the Gestures.

In the majority of the animal communication literature, including some primate studies, the term "multi-modal" has been employed to refer to the combination of information from different sensory channels (e.g., visual, auditory, tactile; Micheletta et al., 2013; Partan, 2002; Partan \& Marler, 1999). However, within nonhuman ape communication this term is sometimes used to refer to the combination of different signal sources (e.g., gesture, vocalization, and/or facial expression; Pollick \& de Waal, 2007; Waller et al., 2013; Wilke et al., 2017). To avoid confusion, here we follow the wider use and employ the term "multi-modal" to refer to the combination of sensory channels, and the term "multi-source" to refer to the combination of signal types.

We took into account the Gestural scope of the study. Here, we defined studies that explored a specific context, or limited set of contexts (e.g., sexual solicitation and consortship), specific gestures, or limited types of gesture (e.g., tactile gestures, or specific gesture forms such as pointing) as Narrow. We defined studies that explored a question across contexts and gesture repertoires without further specification as Broad.

We then asked what Research setting data were collected from. We focused on an individual's familiarity with the environment in which the study data were collected. We defined two main categories: Familiar and Unfamiliar settings. These aimed to capture whether or not the communication studied took place in an environment which was similar to that in which the subjects spent their daily lives. In humans, Familiar settings corresponded to studies conducted in their Homes and Day-care centers, and in Nonhuman primates, corresponded to studies conducted in the areas of daily residence, whether in Wild, Semi-wild, or Captive settings. In both Humans and Nonhuman primates, Unfamiliar settings corresponded to studies conducted in laboratories (e.g., specific research-only rooms). Even when Nonhuman primates visited research-only rooms most days, the setting was classified as Unfamiliar since individuals only spent a small portion of their day in these rooms.

We defined Study design as either Experimental or Observational. In Observational studies, researchers did not manipulate or interact with the subjects and/or their socio-ecological environment (beyond being present). We considered any kind of socio-ecological manipulation across Research Settings as an Experimental design.

\section{5 | Data extraction}

"Research domain" was the only field involving a potentially subjective judgment, so in all cases, two of the authors extracted this field, and any discrepancies were argued until consensus between the two original raters. A third independent opinion was solicited (38 of 221 publications) when the two original raters could not reach consensus, or when the initial disagreement between raters involved more than one domain.

\section{6 | Data analysis}

We compared the number of studies focused on the different research domains and conducted in Human and Nonhuman primates using $\chi^{2}$ tests. The relative contributions of each cell in the computation of $\chi^{2}$ tests are reported through standardized residuals (Std. res.). For changes in the number of studies conducted in each domain over time (response variable) we used a Generalized Linear Model with a Poisson error distribution and log link function. Test predictors included the interaction between domain and year. As an overall test of the effect of the year in the number of studies conducted in the different domains, we compared the full model's deviance with that of a null model comprising only the intercept, and the control predictor (domains). To test the differences across domains, we compared the full model's deviance with that of a reduced model lacking the interactions (between domains and year). All statistical tests were two-tailed and run in $\mathrm{R}$ version 4.0.2. 


\section{3 | RESULTS}

\section{1 | Primate species}

\subsubsection{Which primate species are represented in the review?}

Within the studies of primate gesture that make an explicit connection to understanding the evolution of language, we found a similar number included data on Human $(N=80)$ or Nonhuman $(N=87)$ primates, but only a small set $(N=4)$ included empirical data on both Human and Nonhuman primates. Fifteen of the Nonhuman primate studies included more than one species. Of the Nonhuman primate species studied, the majority focused on Great apes ( $N=75 / 87,86 \%$ ) with a strong bias toward Chimpanzees $(N=56 / 87$, 64\%; see Figure 2). We found no studies of gesture that made an explicit connection to the evolution of language in Small apes, Monkeys of the Americas, or Strepsirrhines.

\subsubsection{How does Socio-ecological environment vary within Nonhuman primates?}

Of the 87 studies of Nonhuman primates, 57 (66\%) were conducted in Captive anthropogenic Species-Atypical environments, and 30 (35\%) were conducted within Wild non-anthropogenic SpeciesTypical environments. No studies included data from Wild primates in anthropogenic Species-Atypical environments.

\subsubsection{How does socioeconomic culture vary within Humans?}

The majority of Human participants were from WEIRD societies $(N=68 / 80,85 \%) ; 10$ studies included Human participants from NonWEIRD industrial societies ( $N=10 / 80,13 \%)$, and two studies included Human participants living in Small-scale nonindustrial societies $(N=2 / 80,3 \%)$.

\section{2 | Research domains}

3.2.1 Which research domains are studied and how does this change over time?

The majority of studies ( $N=153 / 163,94 \%)$ included work on several of the seven research domains (total number of research domains recorded, $N=429$; Table 4). The number of studies varied across these domains (chi-square test: $\chi^{2}=161.4 ; d f=6 ; p<0.001$ ). Meaning represented the most prolific domain of study (Std. res. $=10.722$; $N=139 / 163,85 \%$ ), followed by form (Std. res. $=2.582 ; N=80 / 163$, $49 \%)$. Studies focused on laterality, neural processes, and structure were less frequent (Std. res. $=-3.213,-5.972,-3.765$, respectively) and with neural processes being the least explored domain $(N=18$ / 163, 11\%; Table 4).

The oldest study retained was published in 1975 (note that electronic databases used contain a limited number of publications before the 1950s and only nine publications dated pre-2000 were retained following the abstract and full-text screening phases). Research domains were recorded with increasing frequency year-on-year (full-null model comparison: $\chi^{2}=257.109$; $d f=7 ; p<0.001$ ), however, the increasing rate did not significantly vary across domains (full-reduced model comparison: $\chi^{2}=7.224 ; d f=6 ; p=0.301 ;$ Table 5).

\subsubsection{Which research domains are studied in Human and Nonhuman primates?}

Research effort across research domains was differently distributed in Human and Nonhuman primates (chi-square test: $\chi^{2}=27.204 ; d f=6 ; p<0.001 ;$ Figure 3). Meaning was the most frequently recorded domain in both Human $(N=70 / 80,88 \%)$ and Nonhuman primate $(N=73 / 87,84 \%)$ publications and was similarly represented. Ontogeny was most strongly biased toward Humans (Std. res. $=3.051$ ), and form was most strongly biased toward Nonhuman primates when compared with Humans (Std. res. = 3.548; Figure 3).

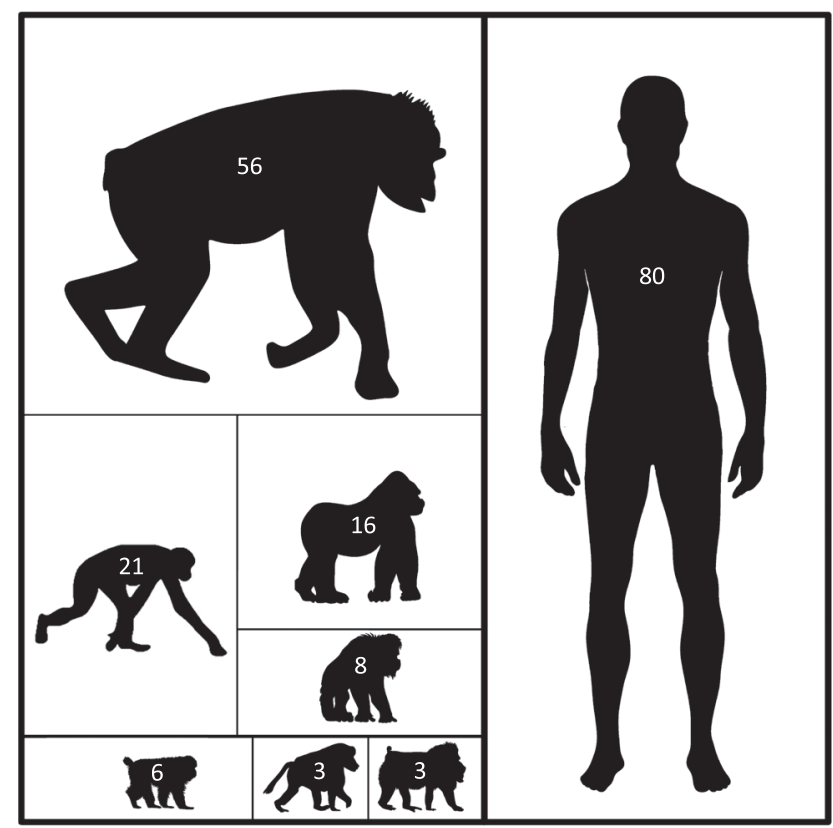

FIGURE 2 Primate species represented in the review. The area represents the number of studies in the review including that species. Nonhuman primates (on the left) include Great apes (chimpanzees, bonobos, gorillas, and orang-utans) and Afro-Eurasian monkeys (macaques, baboons, and mandrills) 


\begin{tabular}{|lllllllll} 
& N & Comb & Form & Lat & Mean & Neur & Ont & Struct \\
\hline Total & 163 & 73 & 80 & 38 & 139 & 18 & 47 & 34 \\
\hline $\begin{array}{l}\text { Gesture definition } \\
\quad\end{array}$ & & & & & & & & \\
$\quad$ Defined & 106 & 44 & 63 & 24 & 93 & 7 & 32 & 16 \\
$\quad$ Not defined & 57 & 29 & 17 & 14 & 46 & 11 & 15 & 18 \\
\hline Intentional criteria & & & & & & & & \\
\hline
\end{tabular}

TABLE 4 Number of studies in each domain according to the Gesture definition, Intentional criteria, Gestural scope, Source, Research setting, and Study design

$\begin{array}{lllllllll}\text { Considered } & 52 & 17 & 39 & 8 & 47 & 0 & 10 & 10 \\ \text { Not considered } & 111 & 56 & 41 & 30 & 92 & 18 & 37 & 24 \\ \begin{array}{l}\text { Body parts } \\ \text { Manual }\end{array} & 88 & 46 & 39 & 26 & 72 & 15 & 29 & 13 \\ \text { Nonmanual } & 7 & 4 & 2 & 2 & 4 & 2 & 2 & 1 \\ \text { Both } & 56 & 21 & 36 & 9 & 52 & 0 & 14 & 12\end{array}$

Gestural scope

$\begin{array}{lllllllll}\text { Broad } & 51 & 17 & 30 & 14 & 46 & 0 & 11 & 11 \\ \text { Narrow } & 112 & 56 & 50 & 24 & 93 & 18 & 36 & 23 \\ \begin{array}{l}\text { Sources } \\ \text { Gesture }\end{array} & 76 & 0 & 44 & 22 & 67 & 5 & 15 & 18 \\ \text { Multisource } & 87 & 73 & 36 & 16 & 72 & 13 & 32 & 16\end{array}$

Research setting

$\begin{array}{lllllllll}\text { Familiar } & 96 & 37 & 58 & 24 & 87 & 0 & 24 & 17 \\ \text { Unfamiliar } & 60 & 31 & 19 & 9 & 47 & 11 & 21 & 16 \\ \text { Both } & 7 & 5 & 3 & 5 & 5 & 7 & 2 & 1\end{array}$

$\begin{array}{lllllllll}\text { Study design } & & & & & & & & \\ \text { Experimental } & 79 & 43 & 24 & 19 & 64 & 18 & 27 & 16 \\ \text { Observational } & 79 & 27 & 54 & 17 & 71 & 0 & 19 & 17 \\ \text { Both } & 5 & 3 & 2 & 2 & 4 & 0 & 1 & 1\end{array}$

Note: The sum of the studies specified by domain for each field differs from the total of studies considered in this analysis because a single study could include more than one domain of gestural research.

Abbreviations: Comb, combination of sources; Form, form; Lat, laterality; Mean, meaning; N, number of publications; Neur, neural processes; Ont, ontogeny; Struct, structure.

\section{3 | Defining gesture and intentional communication}

\subsection{1 | Do studies include an explicit definition for} Gesture and how does it vary with species and domain?

Although all publications had gesture as their main focus, over a third of the studies ( $N=57 / 163,35 \%$ ) did not provide a formal definition for their use of Gesture (or any of the specific forms of Gestures used). A definition of Gesture was more likely to be absent in studies of Humans $(\mathrm{N}=41 / 80,51 \%)$ than in studies of Nonhuman primates $\left(N=16 / 87,18 \%\right.$; chi-square test: $\left.\chi^{2}=18.581 ; d f=1 ; p<0.001\right)$. Only 42 studies explicitly included mechanical ineffectiveness in their definitions of gesture. Studies of Nonhuman primates included reference to mechanical ineffectiveness in their definitions of Gestures $(N=37 / 87,43 \%)$ more so than studies of Humans $(N=5 / 80$, $6 \%$; chi-square test: $\chi^{2}=27.243 ; d f=1 ; p<0.001$ ).

Of the 106 publications that included a definition of Gesture(s), approximately half $(N=52)$ defined only the specific gesture form considered in their studies (e.g., clap, defined as "One hand is brought forcefully downwards, palm facing down, to strike other hand, palm facing upwards; upper hand is recorded as dominant" in Fletcher, 2006) but provided no specific definition of what makes a Gestural signal. The proportion of studies defining gesture differed across domains (chi-square test: $\chi^{2}=18.054 ; d f=6 ; p=0.006$; Table 4). Studies focused on gesture form were the most likely to define Gesture or subtypes of gestures used, and studies focused on neural processes were the least likely to include any definition of Gesture (Std. res. $=2.852$ and -2.376 , respectively). 
TABLE 5 Results of the model (estimates, together with standard errors, confidence intervals, and significant tests)

\begin{tabular}{lllllll}
\hline Terms & Estimate & SE & Lower Cl & Upper Cl & $z$ value & $p$ \\
\hline Intercept) & -209.357 & 52.542 & -324.425 & -116.015 & \\
\hline Domains Form & -100.185 & 80.641 & -263.923 & 57.334 & & a \\
\hline Domains Laterality & -61.053 & 77.288 & -216.596 & 91.426 & & a \\
\hline Domains Meaning & -39.745 & 69.151 & -174.244 & 100.741 & & a \\
\hline Domains Neural processes & -5.944 & 82.719 & -176.749 & 154.343 & & a \\
\hline Domains Ontogeny & 3.194 & 69.615 & -132.627 & 144.387 & & a \\
\hline Domains Structure & -239.809 & 124.467 & -514.930 & -18.625 & & a \\
\hline Year & 0.104 & 0.026 & 0.058 & 0.161 & 3.981 & $<0.001$ \\
\hline Domains Form: Year & 0.050 & 0.040 & -0.028 & 0.131 & 1.246 & 0.213 \\
\hline Domains Laterality: Year & 0.030 & 0.038 & -0.045 & 0.108 & 0.793 & 0.428 \\
\hline Domains Meaning: Year & 0.020 & 0.034 & -0.050 & 0.087 & 0.583 & 0.560 \\
\hline Domains Neural & 0.003 & 0.041 & -0.077 & 0.088 & 0.068 & 0.946 \\
\hline \multicolumn{1}{c}{ processes: Year } & & & & & & \\
\hline Domains Ontogeny: Year & -0.001 & 0.035 & -0.072 & 0.066 & -0.042 & 0.966 \\
\hline Domains Structure: Year & 0.119 & 0.062 & 0.009 & 0.256 & 1.926 & 0.054 \\
\hline
\end{tabular}

Note: Domains were dummy coded with Combination of Sources being the reference category. Abbreviation: $\mathrm{Cl}$, confidence interval.

${ }^{a}$ Not shown because of having a very limited interpretation.

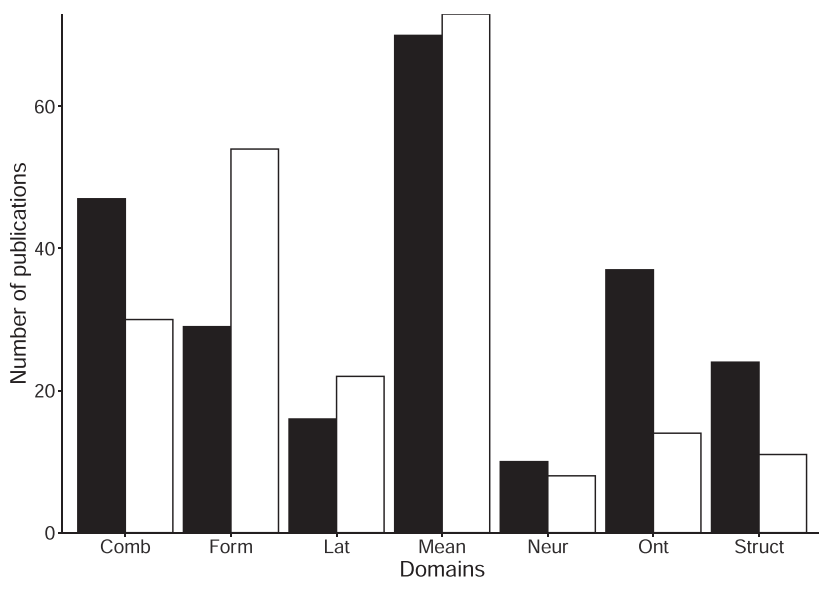

FIGURE 3 Number of studies in Humans and Nonhuman primates across different research domains. Black bars indicate human subjects, white bars nonhuman subjects. Comb, Combination of sources; Form, Form; Lat, Laterality; Mean, Meaning; Neur, Neural processes; Ont, Ontogeny; Struct, Structure. Note that some studies included more than one research domain

Of the 54 studies that provided an explicit definition of gesture, all gestures necessarily included a visual component in their Sensory Modality. Gestures were also defined as compounds that, in addition to visual information, also included an auditory or tactile component in the majority of studies $(N=37 / 54,69 \%$ and $N=40 / 54,74 \%$ respectively; Table 6). In terms of their Social Expression, gestures were defined as produced in the presence of an audience in $89 \%$ of studies ( $N=48 / 54)$; and as addressed to specific recipient(s) in $82 \%$ of studies $(N=44 / 54)$; however, gestures were defined as produced while looking at the recipient in only 6 of the 54 studies (11\%; Table 6). For gestures' Communicative Property, the majority of studies ( $N=51 / 54,94 \%$ ) defined gestures as a subcategory of communicative signals, while only three studies (6\%) defined them as encompassing all communicative signals. Gestures were defined as mechanically ineffective in $69 \%$ of studies $(N=37 / 54)$, and gesture was defined as being followed by a change in the recipient's behavior in most cases $(N=34 / 54,63 \%$; Table 6$)$.

3.3.2 Do studies include a specific definition of and criteria for intentional communication? How does it vary with species and domain?

Specific criteria for intentional communication were only provided in 52 of 163 articles (32\%; Table 4). Of the 54 studies that provided an explicit definition of gesture, $33(61 \%)$ included a requirement that gestures were necessarily an intentional communicative signal. Response waiting and persistence or elaboration were included in approximately half of the studies with a definition of gesture $(N=24 / 54,44 \%$; and $N=28 / 54,52 \%$ respectively). A more recent criterion (Cartmill \& Byrne, 2010; Hobaiter \& Byrne, 2014), gestures were defined in association with an Apparently Satisfactory Outcome in only $9 \%(N=5 / 54)$ of the studies. No studies specified that gestures should not be consistently triggered by specific environmental conditions, and while information on functional context was included in studies, no study required in their definition that gestures be flexible across functions contexts (Table 6). 


\begin{tabular}{|c|c|c|}
\hline Category of criteria & $\begin{array}{l}\text { Specific criteria for defining Communicative } \\
\text { gesture (CG) }\end{array}$ & $\begin{array}{l}\text { Number of } \\
\text { studies }\end{array}$ \\
\hline \multirow[t]{4}{*}{ Body part } & Any body part including face & 5 \\
\hline & Any body part excluding face & 36 \\
\hline & Exclusively manual & 13 \\
\hline & Exclusively facial & 0 \\
\hline \multirow[t]{4}{*}{ Sensory modality } & CG has necessarily a visual component & 53 \\
\hline & CG is visual or visual and auditory & 37 \\
\hline & $\begin{array}{l}\text { CG is visual or visual and vocal (mobilizing the } \\
\text { vocal chords) }\end{array}$ & 0 \\
\hline & CG is visual or visual and tactile & 40 \\
\hline \multirow[t]{3}{*}{ Social expression } & CG is produced in the presence of an audience & 48 \\
\hline & CG is addressed to specific recipient(s) & 44 \\
\hline & CG is produced while looking at the recipient & 6 \\
\hline \multirow[t]{4}{*}{ Communicative property } & CG encompasses all communicative signals & 3 \\
\hline & CG is a subcategory of communicative signals & 51 \\
\hline & CG is mechanically ineffective & 37 \\
\hline & $\begin{array}{l}\text { CG is followed by a change in the recipient's } \\
\text { behavior in most cases }\end{array}$ & 34 \\
\hline \multirow[t]{7}{*}{ Intentional property } & $\begin{array}{l}\text { CG is necessarily an intentional communicative } \\
\text { signal }\end{array}$ & 33 \\
\hline & $\begin{array}{l}\text { CG is produced toward a visually attentive } \\
\text { recipient }\end{array}$ & 2 \\
\hline & $\begin{array}{l}\text { CG is followed by response waiting (a pause in } \\
\text { the gesturer's actions) }\end{array}$ & 24 \\
\hline & $\begin{array}{l}\text { CG is repeated, combined or replaced by other } \\
\text { CGs if no response comes }\end{array}$ & 28 \\
\hline & $\begin{array}{l}\text { CG is not consistently triggered by specific } \\
\text { environmental conditions }\end{array}$ & 0 \\
\hline & CG is expressed in various functional contexts & 0 \\
\hline & $\begin{array}{l}\text { CG is associated with an Apparently Satisfactory } \\
\text { Outcome (ASO) }\end{array}$ & 5 \\
\hline
\end{tabular}

TABLE 6 Number of studies using the criteria proposed by Bourjade et al. (2020) for defining "gesture" 
TABLE 7 Different criteria used by the studies to define intentional gestural communication

\begin{tabular}{llll}
\hline Criteria for intentional gesture & Human & Nonhuman & Total \\
\hline Persistence & 2 & 33 & 34 \\
\hline Response waiting & 1 & 29 & 30 \\
\hline Directed to recipient & 3 & 24 & 27 \\
\hline Audience checking & 2 & 23 & 24 \\
\hline $\begin{array}{l}\text { Sensitivity to the attentional state of } \\
\text { the recipient }\end{array}$ & 1 & 23 & 24 \\
\hline $\begin{array}{l}\text { Goal-directed } \\
\text { Elaboration }\end{array}$ & 1 & 14 & 15 \\
\hline $\begin{array}{l}\text { Change in recipient behavior } \\
\text { Mechanically ineffective }\end{array}$ & 0 & 10 & 10 \\
\hline Ceasing communication when the goal & 0 & 7 & 7 \\
\hline is achieved & 1 & 5 & 6 \\
\hline Attention-getting behavior & 1 & 3 & 5 \\
\hline Initiating social interaction & 0 & 3 & 3 \\
\hline Flexibility & 0 & 2 & 3 \\
\hline
\end{tabular}

Note: Authors often used multiple criteria to define intentional communication. One of the studies using multiple intentional criteria was conducted in both Human and Nonhuman primates; as a result, the sum of the studies with humans and non-humans may exceed the total number of studies that considered each criterion.

Across the full data set, studies of Humans included more Manual gestures than studies of Nonhuman primates $\left(\chi^{2}=10.774\right.$; $d f=2 ; p=0.005)$. Studies differed on the body parts included across all domains $\left(\chi^{2}=21.432 ; d f=12 ; p=0.044\right.$; Table 4). Studies on form were more likely to include both Manual and Nonmanual gestures, and studies on neural processes were more likely to include Manual gestures (Std. res. $=2.206$ and 2.440, respectively).

\section{4 | Scope}

3.4.1 Which type of Scope is represented in the studies included in the review? How does the Scope of the studies vary with species and domain?

Most studies were focused on specific gesture types or specific contexts and were classed as having a Narrow scope $(N=112 / 163$, $69 \%$ ). Studies with a Broad scope were found less often in Human than in Nonhuman primate research $\left(\chi^{2}=18.914 ; d f=1 ; p<0.001\right)$. Although all the domains were explored more often using a Narrow scope, the extent of this bias varied across domains $\left(\chi^{2}=13.948\right.$; $d f=6 ; p=0.030$ ) with form and laterality least biased (Std. res. $=$ -1.606 and -0.954 respectively), as compared to neural processes which were exclusive studied with a Narrow scope (Std. res. $=2.842$; Table 4).

\subsection{Sources}

\subsection{1 | Do studies incorporate additional Sources as} well as Gesture? How does Source vary with species and domain?

Approximately half of the studies ( $N=87 / 163$ ) considered additional sources to gesture. Vocalizations were considered in almost all multisource studies ( $N=81 / 87,93 \%$ ), whereas Facial expressions and Lexigrams were described in $17 \%$ of multisource studies ( $N=15 / 87)$. Nine articles considered two or more sources in addition to Gesture. Studies conducted in Humans $(N=53 / 80,66 \%)$, as compared with Nonhuman Primates ( $N=37 / 87,43 \%$ ), were more likely to include a multisource approach $\left(\chi^{2}=8.507 ; d f=1 ; p=0.004\right)$. Studies of gesture in Humans including data on Vocalizations ( $N=51 / 80 ; 64 \%)$ more often than studies conducted in Nonhuman primates $(N=33$ / $87,38 \%)$. The proportion of studies considering multiple sources varied across research domains $\left(\chi^{2}=69.984 ; d f=6 ; p<0.001\right)$, with a multisource approach always occurring in studies focused on combination of sources (Std. res. $=7.635$ ), and less frequently on studies focused on form, laterality, and meaning (Std. res. $=-3.066,-2.378$, and -2.443 , respectively).

\section{6 | Research setting}

\subsubsection{Which Research settings are represented,} and how do these vary with species and domain?

Most of the studies were conducted in Familiar settings ( $N=96 / 163$, $59 \%)$. The frequency with which different Research settings were used varied across Human and Nonhuman primates $\left(\chi^{2}=61.578\right.$; $d f=2 ; p<0.001)$. Studies of Nonhuman primates were conducted more often in Familiar settings ( $N=71 / 87,82 \%)$, and studies with Humans were conducted more often in Unfamiliar settings ( $N=53$ / 80, 68\%; Table 8).

Research settings used also varied across Research domains (chisquare test: $\chi^{2}=62.12 ; d f=12 ; p<0.001$ ). Form was studied most often in Familiar settings and neural processes were usually studied in Unfamiliar settings (Std. res. $=2.995$ and 2.278, respectively; Table 4).

\section{7 | Study design}

\subsubsection{Which Study designs are represented and how does the Study design vary with species and domain?}

Both Observational ( $n=79 / 163,49 \%$ ) and Experimental $(n=79 / 163$, 49\%) designs were employed equally frequently in these studies; five studies incorporated both designs (3\%). Studies with Humans applied Experimental designs more often ( $n=58 / 80,73 \%)$, and studies with 
TABLE 8 Number of studies discriminated by Research Setting

$\begin{array}{lll}\text { Research setting } & \text { Human } & \text { Nonhuman } \\ \text { Familiar } & 5 & - \\ \text { Daycare } & 19 & - \\ \text { Home } & 1 & - \\ \text { Daycare + Home } & - & 35 \\ \text { Captivity } & - & 30 \\ \text { Wild } & - & 1 \\ \text { Captivity + Wild } & - & 5 \\ \text { Sanctuaries } & & 7 \\ \text { Unfamiliar } & 53 & 7 \\ \text { Laboratory } & & 2 \\ \text { Both } & - & \\ \text { Captivity + Laboratory } & 2 & \\ \text { Home (H) + Laboratory (NH) } & \end{array}$

Nonhuman primates applied Observational designs more often ( $n=61 / 87,70 \%$; chi-square test: $\chi^{2}=35.846 ; d f=2 ; p<0.001$ ).

The relative use of Observational and Experimental designs varied significantly across domains (chi-square test: $\chi^{2}=37.317$; $d f=12 ; p<0.001$ ). Studies analyzing form used Observational designs most often, whereas studies focused on neural processes were always Experimental (Std. res. $=3.914$ and 4.406, respectively; Table 4).

\section{4 | DISCUSSION}

Studies of gestural communication that make an explicit connection to the evolutionary origins of language exist in similar numbers for both human and nonhuman primates; however, only four of the 163 studies included in this review incorporated data from both human and nonhuman primates, and only 15 included more than one nonhuman primate species. As a result, our ability to investigate species' similarities and distinctions across primate taxa and infer an evolutionary trajectory for language from this field, is almost entirely dependent on comparison across studies. By conducting a systematic review, we are able to describe to what extent current methods allow us to do so reliably. We find substantial variation in the conceptual and methodological approaches used. While variation allows for a diverse and robust examination of gesture in this context, it presents particular challenges for the effective comparison across studies and species on which the evolutionary approach depends.

There were limitations to the literature returned in our search process, for example, older material (particularly pre-1950) is not systematically indexed in electronic databases. However, perhaps the most important one was in our requirement for an explicit reference to the evolution or origins of language or communication. We were initially surprised that, in employing this restriction, we excluded work we regularly cite as relevant to the evolutionary origins of human language, including our own studies. Removing the requirement for the "evolutionary" terms from our search returned around 6500 results; whereas with them, our structured search returned around a thousand items (with just over a sixth of that retained once the systematic selection criteria had been applied). One explanation for the extent of these exclusions is that many of the empirical studies on nonhuman primate gesture (including our own) avoid explicit discussion of their potential connection to the evolution of human language-and in particular, do not do so in the title, keywords, or abstract; the fields most commonly indexed across databases. In some cases, not doing so may be because the primary focus of the study was a description of the species communication-nonhuman primate gesture is of interest in its own right, not just as a means of comparison to human communication. Nevertheless, these studies may usefully inform our understanding of the evolutionary trajectory of linguistic features. For example, some studies that explore the combination of gestures into sequences (e.g., McCarthy et al., 2013; Tempelmann \& Liebal, 2012), relevant to understanding similarities and differences to human language structure, or studies on neural processes of homologous brain area activation in human and nonhuman primate signaling (e.g., Hopkins et al., 2007, 2008) were excluded because they did not make an explicit connection to the evolution of language. Similarly, some studies of human gesture discussed its relationship to individual ontogeny of language, but did not explicitly consider the relevance of the work to the evolution of language (e.g., Bates et al. 1979; Iverson et al., 1994).

While widening our search to more broadly encompass primate gestural research would successfully retain these studies, it would also add a very large literature that provides limited insight into the evolution of language (e.g., work on leaf-clipping as a sexual solicitation in chimpanzees; Nishida, 1980; or work on big loud scratch as grooming solicitation; Nakamura et al., 2000) and such a large corpus risks diluting our ability to provide a clear overview of the field. There may also be a justifiable reluctance to engage in "just-so story-telling" in research that does not explicitly test evolutionary hypotheses. Spurious statements about the relevance of any nonhuman primate behavior to human behavior unhelpfully reinforce human-centric approaches to the study of nonhuman behavior, which risk us overlooking extraordinary nonhuman species-specific capacities. Whereas carefully considered discussions can be helpful, they require a substantial investment that may distract from the main aim of research that did not set out to explicitly further a comparative approach. Nevertheless, our theoretical studies often use the findings from these same empirical studies of primate gesture as the foundation for the hypotheses we develop on the evolution of human language. While it is certainly the case that studies of nonhuman primate gesture contribute to a much wider range of questions beyond the possible evolutionary origins of human language, it may be worth reflecting on the apparent scope in our field to more explicitly test evolutionary hypotheses in a wider range of our empirical work. For example, by establishing multispecies primate data sets that employ a coherent study methodology, or allow for the extraction of 
like-with-like features for comparison, we can test hypotheses that address how aspects of gesture are adapted to a particular species socio-ecology (cf. Prieur et al., 2020).

Developing hypotheses on the evolution of behavior within primate history requires that we have sufficient rich data across, and within, primate taxa. However, we found that studies of nonhuman primate gestural communication were largely limited to chimpanzees and bonobos. A number of studies in monkeys were excluded because they involved training them to produce a particular gesture (e.g., Defolie et al., 2015; Meunier et al., 2013) leaving only a handful of studies in Afro-Eurasian monkeys, and no studies on monkeys of the Americas, small apes, or strepsirrhines. While chimpanzees and bonobos represent our closest living relatives, and these studies allow us to ask whether or not a particular feature of language is uniquely human, they provide a more limited scope for exploring the possible evolutionary trajectory of language over a longer period. In addition, implicit hierarchies exist between species in their relevance to human origins that may obscure the deeper roots of some features (Bourjade et al., 2020). We see this illustrated in our data in the very limited number of human studies that explicitly test whether the gestures explored meet criteria for intentional use-there is an assumption that human behavior always does. Our findings similarly highlight that there is often an implicit assumption of the importance of ape behavior for understanding human evolution, whereas studies of monkey behavior are required to more thoroughly establish the grounds for comparison (Bourjade et al., 2020). Data on the spontaneous gestural communication from a more diverse range of species-including direct comparisons between nonhuman primatesare necessary for a deeper and more nuanced understanding of how and when the capacities that underpin language evolved.

Our understanding of gestural signals' contribution to the evolutionary origins of human language may also be compromised by the use of specific human and nonhuman primate populations to represent species-specific characteristics. Every species' system of communication-including primate gesturing-is in some way adapted to a species' specific and distinct socio-ecological niche (Cheney \& Seyfarth, 2018). The majority of studies of nonhuman primate gesture in our review were conducted on groups living in man-made anthropogenic environments that do not reflect the socio-ecological environments to which their communication is adapted. Even among studies of wild primates, a focus on a few specific groups or populations (e.g., Hobaiter \& Byrne, 2011a; Pika \& Mitani, 2006; Roberts et al., 2012), likely impacts our understanding of species-typical behavior. Similarly, in human studies there was also a focus on specific groups: as in many fields of study (Henrich et al., 2010), there was a strong bias toward studies of human gesture in WEIRD socioeconomic cultures. Our understanding of the links between primate gesture and human language can be strengthened by more direct testing of the impact of species socio-ecology and individual lifehistory characteristics on gestural expression (e.g., Prieur et al., 2020), although doing so will take substantial large-scale data sets.

Different environments may promote the use of certain gestures that are not expressed in other environments (see Leavens, Russell, et al., 2005 for the example of pointing). The frequency and quality (context, interaction partner, and group membership) of interactions seem to influence the frequency of gesture use and the size of gestural repertoires, for example, higher interaction rates with nonmaternal conspecifics and a larger number of previous interaction partners are both related to more frequent gesturing and the use of more gesture types (Fröhlich et al., 2017, 2018). Thus, it is particularly important to complement the detailed data from captive settings with more diverse data from primates living in their naturally structured social units (Cheney \& Seyfarth, 2018; Fröhlich \& Hobaiter, 2018). Given the well-established presence of rich cultural variation in behavior (Boesch et al., 1994; McGrew et al., 1997; Whiten et al., 1999) a richer understanding of the communicative abilities in diverse populations, in a range of environments (Hobaiter \& Byrne, 2011b, 2014), in other great apes (gorillas, bonobos, and orang-utans; Bard, 1992; Genty et al., 2009; Knox et al., 2019; Schamberg et al., 2016), and in other primate species (e.g., Japanese macaques, mandrills, pygmy marmosets, capuchin monkeys, bonnet macaques; De La Torre \& Snowdon, 2002; Gupta \& Sinha, 2016; Itani, 1963; Kudo, 1987; Wheeler, 2010) is necessary to better understand the evolutionary trajectory of primate gestural communication and its relationship with language.

The steady increase across most domains highlights the increasing interest in, and relevance of gesture to, questions related to language evolution; however, research efforts remain unequally distributed across domains and between species within domains. Meaning was the most popular domain and was similarly explored in both human and nonhuman primates. Studies of form were most biased toward nonhuman primates and ontogeny were most biased toward studies in humans.

Studies of meaning in gestural communication are now the most common focus. Gestural research has sometimes employed the signaller's behavior or the context of the signal use as a proxy for "meaning" (Bard \& Leavens, 2014; Tomasello et al., 1994). Reflecting gesture's intentional use, recent studies employ a combination of signaller and recipient behavior to take a cognitive-linguistic perspective and infer the signaller's intended meaning (e.g., Cartmill \& Byrne, 2010; Genty et al., 2009; Graham et al., 2017; Hobaiter \& Byrne, 2014). The large number of studies of signal form in other primates is likely because this domain includes the description of communicative repertoires, a common focus when exploring the communication of any nonhuman species (e.g., Berg, 1983; Conner, 1985; Edds-Walton \& Edds-Walton, 1997). However, the lack of similar systematic descriptive studies of human gesture forms again makes comparison with nonhuman primate research challenging (Kersken et al., 2018; Müller, 2005). Gestural ontogeny has been explored in humans for decades in the context of its relevance for language development; however, it is only more recently that researchers started to frame their results within the evolutionary puzzle or explore this domain in nonhuman primates.

Both within and between human and nonhuman primates, studies used different definitions of which movements and body parts constitute a gesture, and different criteria to define their intentional 
use. Some studies defined gesture broadly to include body postures, while other studies employed more restrictive definitions including specific criteria, or specific body parts. Over half of the studies were restricted to manual gestures, but a considerable number of studies ( 40\%) were more flexible, including movements from the whole body or other body parts. None of this variation is necessarily problematic; however, a significant cause for concern, given this variation in definition, is that more than a third of the studies in this review did not provide a definition for their use of gesture at all. These differences in the fundamental basis of what "a gesture" is may have significant consequences for the study of comparative communication: particularly where different studies across different species are directly compared. It would be unnecessarily limiting to require a single definition of gesture, and, for example, there is no particular problem with considering only manual gestures. However, given the variation across the field, to allow effective comparison across species and populations, it is imperative that studies define their specific usage.

One aspect of gesture form we did not directly compare was gestural repertoires. Composed of graded movements (e.g., from shake to swing or reach to fling), the identification of distinct gesture forms is typically done from the subjective and anthropocentriccentric perspective of the researcher(s) (cf. Hobaiter et al., 2017). Even within a research group there may be variation between studies; for example, where more data become available or new species comparisons suggest previously undetected similarities or differences of form (cf. Byrne et al., 2017; Genty et al., 2009; Graham et al., 2017; Hobaiter \& Byrne, 2011b; Knox et al., 2019). Descriptions of repertoires take substantial study effort (Byrne et al., 2017; Hobaiter \& Byrne, 2011b), and are vulnerable to undersampling (Knox et al., 2019)-making comparison across studies particularly valuable. However, our current ability to do so remains very limited: under a third of the studies, we analyzed provided any description of their specific gesture form(s). Even where written descriptions are available, these can be difficult to interpret. As open-access online dataarchiving becomes increasingly accessible, the use of video examples (e.g., www.greatapedictionary.com) highlighting both the archetypical form and variation around it, will make a substantial contribution to our ability to systematically compare like-with-like within gesture form, without necessitating the use of universal-and potentially restrictive-agreed repertoires.

The use of a clear framework for comparison allows us to highlight not only the variation in the frequency with which criteria for intentional gesture use are applied, but also differences in the types of criteria used between human and nonhuman primates (Bourjade et al., 2020). Once again, across studies and across human and nonhuman primates, we find substantial variation. Where definitions were available, persistence was the most popular criterion, with gestures considered intentional when the signaller persists in producing further gestures if a response is not obtained from the recipient. The criteria for defining intentional communication were originally developed to explore the development of prelinguistic communication in human infants (Bates et al., 1975, 1979), but their explicit use seems now largely restricted to nonhuman primate studies. Over half of the nonhuman primate studies reviewed provided some criteria for defining intentional gesture. However, while many required gesture cases to meet one or more criteria for intentional use from a set, they typically did not specify which were met (Genty et al., 2009; Hobaiter \& Byrne, 2011b; cf. Leavens, Hopkins, et al., 2005). No one criterion is a panacea for the challenge of identifying mental states from observable behavior. Audiencechecking could simply reflect a shift in attention between objects of interest. Response-waiting could reflect a brief rest in activity. Providing more detail on the frequency and distribution of the different criteria within a study would allow for a more direct comparison of intentional gesture use across studies and species of nonhuman primates and improve our ability to assess the extent to which particular criteria provide robust, reliable, measures (e.g., Prieur et al., 2018).

In contrast to the relatively widespread use of criteria to define intentional gesture in nonhuman primates, just four studies in humans and one on both human and nonhuman primates, provided any criteria for intentional gesture use. While humans are clearly capable of intentional communication, we are equally capable of producing fixed non-intentional signals (e.g., an involuntary yelp, smile, or laugh; Kawakami et al., 2007; Provine, 1992). Moreover, mechanically ineffectiveness seems to be a criterion often applied in nonhuman primate research to define gesture, but rarely seen in human gestural research. Including all human gesture-like movements, irrespective of the objective evidence for their communicative and intentional use, while limiting nonhuman primate data to only those gestures used with evidence for intentional use, again, impacts our ability to make meaningful comparisons between human and nonhuman gesture. Doing so furthers the double standard too often applied in comparative research, which sees systematic species-differences in testing conditions or criteria mistaken for species-differences in cognition (Bard \& Leavens, 2014; Leavens et al., 2019).

The majority of the studies reviewed employed a narrow scope of focus, investigating specific gesture types or specific contexts. However, studies in nonhuman primates were more likely to have a broad scope than studies with humans; for example, they more often included descriptions of gestural repertoires rather than a specific form such as pointing. Again, there is no intrinsic benefit to employing a narrow or broad scope, but both are needed across species to compare like with like.

Almost half the studies in this review included other signal sources with their gesture data; however, the integration of gestures, vocalizations, and facial expressions remains understudied in nonhumans relative to humans, despite recent calls to investigate it (e.g., Slocombe et al., 2011; Waller et al., 2013). Where signal sources are combined in communication, for example, gesture and facial expression, studying one in the absence of the other may limit our interpretation of signal function (Wilke et al., 2017). However, studying different signal types and sources in combination can be methodologically challenging. For example, studies of gesture often focus on visual information, and the signaller and recipient's visual attention; neither of which may be as relevant to the production or 
receipt of vocal signals (Schel et al., 2013). The development of methodologies that can be applied across sources will allow for more widespread multisource comparisons (Müller, 2005; Slocombe et al., 2011).

Ape cognitive and social development, including in their communicative repertoires (Boesch, 2007; Leavens et al., 2019), is sensitive to a wide range of social and environmental factors, and interactional experience has been shown to impact the development of gestural use (e.g., Bard et al., 2014; Fröhlich \& Hobaiter, 2018). We found that nonhuman primates were more often studied in environments that were familiar to them and used observational research designs. In contrast, human research was mainly conducted in unfamiliar environments, such as research laboratories, and used experiment designs. Collecting data within a laboratory setting allows nuanced control of specific variables; however, these methods are typically challenging to replicate in an ethical manner with nonhuman primates. Slocombe et al. (2011) previously highlighted the lack of nonhuman primate gestural work in the wild (although see now e.g., Graham et al., 2018; Hobaiter \& Byrne, 2011a, 2011b; Roberts et al., 2012), but it is similarly noteworthy that very little gestural work on humans is done outside of unfamiliar laboratory settings (cf. Kersken et al., 2018).

Diversity in definitions and methods allows for robust testing of a particular line of research, with different perspectives and findings contributing to a deeper and more nuanced understanding of the question. As a result, it is critical that we allow researchers' sufficient flexibility in their definition of and exploration of primate gesture. Without this, we would only stifle comparison-potentially missing crucial similarities and differences. However, where diversity is present, the absence of definitions and transparent descriptions of methods is a problemparticularly so as our ability to make explicit points about the evolution of a particular aspect of language often depends on comparison across species and studies.

We can summarize our findings in the following 8-point call to action for researchers interested in how gestural communication may inform our understanding of language evolution.

There is substantial scope in the wider gestural field to more explicitly test evolutionary hypotheses in our empirical work.

Data are needed on spontaneous gestural communication from a more diverse range of species, in particular, outside of Pan ape species, and including direct comparisons between nonhuman primates.

Data are needed from more diverse populations in diverse environments that consider the impact of socio-ecology and socioeconomy on the use of gesture.

There is particular scope for studies of gesture forms in humans, and studies of gesture ontogeny in nonhuman primates.

Given the variation across the field, it is imperative that studies define their specific usage of gesture.

Providing more detail on the frequency and distribution of the different criteria for intentional use, in particular in humans, will improve our ability to assess the extent to which particular criteria provide robust, reliable, measures.
The development of methodologies that can be applied across sources will allow for more widespread multisource comparisons.

In addition to studies of human gesture outside WEIRD populations, there is also substantial scope for studies of natural human gesture in familiar, non-laboratory, environments.

We hope that this review serves to highlight not only the challenges, but also the areas of particular promise for future research. A detailed understanding of human and nonhuman primate gesture will take more than one researcher's or research group's lifetime of study. Diversity in our study subjects and approach will provide a more nuanced understanding, but transparency and replicability in our methods are equally crucial to our ability to draw meaningful conclusions about gestural communication's role in the evolution of human language.

\section{ACKNOWLEDGMENTS}

The structure of this study was developed during the January 2019 ISPA Advanced Course on Scientific Writing, and we would like to thank P. McGregor for his guidance. We are grateful for the thoughtful comments raised in the review process that allowed us to incorporate important new analyses and discussion. The authors gratefully acknowledge the financial support provided by the Portuguese Foundation for Science and Technology to the first author (SFRH/BD/138406/2018).

\section{CONFLICT OF INTERESTS}

The authors declare that there are no conflict of interests.

\section{DATA AVAILABILITY STATEMENT}

The data that supports the findings of this study are available in the Supporting Information Material of this article and in a public repository on github.com/Wild-Minds/GestureStudies_SystematicReview

\section{REFERENCES}

Arensburg, B., Tillier, A. M., Vandermeersch, B., Duday, H., Schepartz, L. A., \& Rak, Y. (1989). A Middle Palaeolithic human hyoid bone. Nature, 338(6218), 758-760. https://doi.org/10.1038/ $338758 \mathrm{a} 0$

Bard, K. A. (1992). Intentional behavior and intentional communication in young free-ranging orangutans. Child Development, 63(5), 1186-1197. https://doi.org/10.1111/j.1467-8624.1992.tb01688.x

Bard, K. A., Dunbar, S., Maguire-Herring, V., Veira, Y., Hayes, K. G., \& Mcdonald, K. (2014). Gestures and social-emotional communicative development in chimpanzee infants. American Journal of Primatology, 76(1), 14-29. https://doi.org/10.1002/ajp.22189

Bard, K. A., \& Hopkins, W. D. (2018). Early socioemotional intervention mediates long-term effects of atypical rearing on structural covariation in gray matter in adult chimpanzees. Psychological Science, 29(4), 594-603. https://doi.org/10.1177/0956797617740685

Bard, K. A., \& Leavens, D. A. (2014). The importance of development for comparative primatology. Annual Review of Anthropology, 43(1), 183-200. https://doi.org/10.1146/annurev-anthro-102313-030223

Bates, E., Benigni, L., Bretherton, I., Camaioni, L. \& Volterra, V. (1979). The emergence of symbols.

Bates, E., Camaioni, L., \& Volterra, V. (1975). The acquisition of performatives prior to speech. Merrill-Palmer Quarterly of Behavior and Development, 21(3), 205-226. 
Berg, J. K. (1983). Vocalizations and associated behaviors of the African elephant (Loxodonta africana) in captivity. Zeitschrift für Tierpsychologie, 63(1), 63-79. https://doi.org/10.1111/j.14390310.1983.tb00741.x

Biau, E., Morís Fernández, L., Holle, H., Avila, C., \& Soto-Faraco, S. (2016). Hand gestures as visual prosody: BOLD responses to audio-visual alignment are modulated by the communicative nature of the stimuli. Neurolmage, 132, 129-137. https://doi.org/10.1016/j. neuroimage.2016.02.018

Boesch, C. (2007). What makes us human (Homo sapiens)? The challenge of cognitive cross-species comparison. Journal of Comparative Psychology, 121(3), 227-240. https://doi.org/10.1037/0735-7036. 121.3.227

Boesch, C. (2020). The human challenge in understanding animal cognition. In L. S. M. Johnson, A. Fenton, \& A. Shriver (Eds.), Neuroethics and nonhuman animals (pp. 33-51). Springer International Publishing. https://doi.org/10.1007/978-3-03031011-0_3

Boesch, C., Marchesi, P., Marchesi, N., Fruth, B., \& Joulian, F. (1994). Is nut cracking in wild chimpanzees a cultural behaviour? Journal of Human Evolution, 26(4), 325-338. https://doi.org/10.1006/jhev.1994.1020

Bolhuis, J. J., Tattersall, I., Chomsky, N., \& Berwick, R. C. (2014). How could language have evolved? PLOS Biology, 12(8), e1001934. https://doi.org/10.1371/journal.pbio.1001934

Bourjade, M., Cochet, H., Molesti, S., \& Guidetti, M. (2020). Is conceptual diversity an advantage for scientific inquiry? A case study on the concept of 'gesture' in comparative psychology. Integrative Psychological and Behavioral Science, 54(4), 805-832. https://doi. org/10.1007/s12124-020-09516-5

Brentari, D., Coppola, M., Mazzoni, L., \& Goldin-Meadow, S. (2012). When does a system become phonological? Handshape production in gesturers, signers, and homesigners. Natural Language \& Linguistic Theory, 30(1), 1-31. https://doi.org/10.1007/s11049-011-9145-1

Byrne, R. W., Cartmill, E., Genty, E., Graham, K. E., Hobaiter, C., \& Tanner, J. (2017). Great ape gestures: Intentional communication with a rich set of innate signals. Animal Cognition, 20(4), 755-769. https://doi.org/10.1007/s10071-017-1096-4

Cartmill, E. A., \& Byrne, R. W. (2010). Semantics of primate gestures: Intentional meanings of orangutan gestures. Animal Cognition, 13(6), 793-804. https://doi.org/10.1007/s10071-010-0328-7

Cheney, D. L., \& Seyfarth, R. M. (2018). Flexible usage and social function in primate vocalizations. Proceedings of the National Academy of Sciences of the United States of America, 115, 1974-1979. https:// doi.org/10.1073/pnas.1717572115

Christiansen, M. H., \& Chater, N. (2015). The language faculty that wasn't: A usage-based account of natural language recursion. Frontiers in Psychology, 6, 1182. https://doi.org/10.3389/fpsyg.2015.01182

Conner, R. N. (1985). Vocalizations of common ravens in Virginia. The Condor, 87(3), 379-388. https://doi.org/10.2307/1367219

Cooke, A., Smith, D., \& Booth, A. (2013). Qualitative health research beyond PIC: The SPIDER tool for qualitative evidence synthesis. Qualitative Health Research, 22(10), 1435-1443. https://doi.org/10. 1177/1049732312452938

Corballis, M. C. (2002). From hand to mouth: The origins of language. Princeton University Press. https://doi.org/10.1525/jlin.2006.16. 1.146

De La Torre, S., \& Snowdon, C. T. (2002). Environmental correlates of vocal communication of wild pygmy marmosets, Cebuella pygmaea. Animal Behaviour, 63(5), 847-856. https://doi.org/10.1006/anbe. 2001.1978

Defolie, C., Malassis, R., Serre, M., \& Meunier, H. (2015). Tufted capuchins (Cebus apella) adapt their communicative behaviour to human's attentional states. Animal Cognition, 18(3), 747-755. https://doi.org/ 10.1007/s10071-015-0841-9
Edds-Walton, P. L., \& Edds-Walton, P. L. (1997). Acoustic communication signals of mysticete whales. Bioacoustics, 8(1-2), 47-60. https://doi. org/10.1080/09524622.1997.9753353

Fletcher, A. W. (2006). Clapping in chimpanzees: Evidence of exclusive hand preference in a spontaneous, bimanual gesture. American Journal of Primatology, 68(11), 1081-1088. https://doi.org/10.1002/ ajp.20308

Fröhlich, M., \& Hobaiter, C. (2018). The development of gestural communication in great apes. Behavioral Ecology and Sociobiology, 72(12), 194. https://doi.org/10.1007/s00265-018-2619-y

Fröhlich, M., Müller, G., Zeiträg, C., Wittig, R. M., \& Pika, S. (2017). Gestural development of chimpanzees in the wild: The impact of interactional experience. Animal Behaviour, 134, 271-282. https:// doi.org/10.1016/J.ANBEHAV.2016.12.018

Fröhlich, M., Sievers, C., Townsend, S. W., Gruber, T., \& Schaik, C. P. (2019). Multimodal communication and language origins: Integrating gestures and vocalizations. Biological Reviews, 94(5), 1809-1829. https://doi.org/10.1111/brv.12535

Fröhlich, M., Wittig, R. M., \& Pika, S. (2018). The ontogeny of intentional communication in chimpanzees in the wild. Developmental Science, 22(1), e12716. https://doi.org/10.1111/desc.12716

Genty, E., Breuer, T., Hobaiter, C., \& Byrne, R. W. (2009). Gestural communication of the gorilla (Gorilla gorilla): Repertoire, intentionality and possible origins. Animal Cognition, 12(3), 527-546. https://doi.org/10.1007/s10071-009-0213-4

Gillespie-Lynch, K., Greenfield, P. M., Lyn, H., \& Savage-Rumbaugh, S. (2014). Gestural and symbolic development among apes and humans: Support for a multimodal theory of language evolution. Frontiers in Psychology, 5, 1228. https://doi.org/10.3389/fpsyg. 2014.01228

Goldin-Meadow, S., \& Yang, C. (2017). Statistical evidence that a child can create a combinatorial linguistic system without external linguistic input: Implications for language evolution. Neuroscience \& Biobehavioral Reviews, 81, 150-157. https://doi.org/10.1016/j. neubiorev.2016.12.016

Graham, K. E., Furuichi, T., \& Byrne, R. W. (2017). The gestural repertoire of the wild bonobo (Pan paniscus): A mutually understood communication system. Animal Cognition, 20(2), 171-177. https:// doi.org/10.1007/s10071-016-1035-9

Graham, K. E., Hobaiter, C., Ounsley, J., Furuichi, T., \& Byrne, R. W. (2018). Bonobo and chimpanzee gestures overlap extensively in meaning. PLOS Biology, 16(2), 2004825. https://doi.org/10.1371/journal.pbio. 2004825

Gupta, S., \& Sinha, A. (2016). Not here, there! Possible referential gesturing during allogrooming by wild bonnet macaques, Macaca radiata. Animal Cognition, 19(6), 1243-1248. https://doi.org/10. 1007/s10071-016-1012-3

Hall, M. L., Ahn, Y. D., Mayberry, R. I., \& Ferreira, V. S. (2015). Production and comprehension show divergent constituent order preferences: Evidence from elicited pantomime. Journal of Memory and Language, 81, 16-33. https://doi.org/10.1016/j.jml.2014.12.003

Hauser, M. D., Chomsky, N., \& Fitch, W. T. (2002). The faculty of language: What is it, who has it, and how did it evolve? Science (New York, N.Y.), 298(5598), 1569-1579. https://doi.org/10.1126/ science.298.5598.1569

Henrich, J., Heine, S., \& Nature, A. N. (2010). Most people are not WEIRD. Nature, 466(7302), 29.

Hewes, G. W., Andrew, R. J., Carini, L., Choe, H., Gardner, R. A., Kortlandt, A., Krantz, G. S., McBride, G., Nottebohm, F., Pfeiffer, J., Rumbaugh, D. G., Steklis, H. D., Raliegh, M. J., Stopa, R., Suzuki, A., Washburn, S. L., \& Wescott, R. W. (1973). Primate communication and the gestural origin of language [and comments and reply]. Current Anthropology, 14(1-2), 5-24. https://doi.org/10.1086/ 201401 
Hobaiter, C., \& Byrne, R. W. (2011a). Serial gesturing by wild chimpanzees: Its nature and function for communication. Animal Cognition, 14, 827-838. https://doi.org/10.1007/s10071-011-0416-3

Hobaiter, C., \& Byrne, R. W. (2011b). The gestural repertoire of the wild chimpanzee. Animal Cognition, 14(5), 745-767. https://doi.org/10. 1007/s10071-011-0409-2

Hobaiter, C., \& Byrne, R. W. (2014). The meanings of chimpanzee gestures. Current Biology, 24(14), 1596-1600. https://doi.org/10. 1016/j.cub.2014.05.066

Hobaiter, C., \& Byrne, R. W. (2017). What is a gesture? A meaning-based approach to defining gestural repertoires. Neuroscience \& Biobehavioral Reviews, 82, 3-12. https://doi.org/10.1016/j. neubiorev.2017.03.008

Hobaiter, C., Byrne, R. W., \& Zuberbühler, K. (2017). Wild chimpanzees' use of single and combined vocal and gestural signals. Behavioral Ecology and Sociobiology, 71(6), 96. https://doi.org/10.1007/ s00265-017-2325-1

Hopkins, W. D., Dunham, L., Cantalupo, C., \& Taglialatela, J. (2007). The association between handedness, brain asymmetries, and corpus callosum size in chimpanzees (Pan troglodytes). Cerebral Cortex, 17(8), 1757-1765. https://doi.org/10.1093/cercor/bhl086

Hopkins, W. D., Taglialatela, J. P., Meguerditchian, A., Nir, T., Schenker, N. M., \& Sherwood, C. C. (2008). Gray matter asymmetries in chimpanzees as revealed by voxel-based morphometry. Neurolmage, 42(2), 491-497. https://doi.org/10.1016/j. neuroimage.2008.05.014

Hsieh, S., \& Plotnick, R. E. (2020). The representation of animal behaviour in the fossil record. Animal Behaviour, 169, 65-80. https://doi.org/ 10.1016/j.anbehav.2020.09.010

Itani, J. (1963). Vocal communication of the wild Japanese monkey. Primates, 4(2), 11-66. https://doi.org/10.1007/bf01659149

Iverson, J. M., Capirci, O., \& Caselli, M. C. (1994). From communication to language in two modalities. Cognitive Development, 9(1), 23-43. https://doi.org/10.1016/0885-2014(94)90018-3

Kawakami, K., Takai-Kawakami, K., Tomonaga, M., Suzuki, J., Kusaka, F., \& Okai, T. (2007). Spontaneous smile and spontaneous laugh: An intensive longitudinal case study. Infant Behavior and Development, 30(1), 146-152. https://doi.org/10.1016/j.infbeh.2006.08.004

Kersken, V., Gómez, J.-C., Liszkowski, U., Soldati, A., \& Hobaiter, C. (2018). A gestural repertoire of 1- to 2-year-old human children: In search of the ape gestures. Animal Cognition, 22, 577-595. https://doi.org/10. 1007/s10071-018-1213-z

Knox, A., Markx, J., How, E., Azis, A., Hobaiter, C., van Veen, F. J. F., \& Morrogh-Bernard, H. (2019). Gesture use in communication between mothers and offspring in wild orang-utans (Pongo pygmaeus wurmbii) from the Sabangau Peat-Swamp Forest, Borneo. International Journal of Primatology, 40, 393-416. https:// doi.org/10.1007/s10764-019-00095-w

Kudo, H. (1987). The study of vocal communication of wild mandrills in Cameroon in relation to their social structure. Primates, 28(3), 289-308. https://doi.org/10.1007/BF02381013

Leavens, D. A., Bard, K. A., \& Hopkins, W. D. (2010). BIZARRE chimpanzees do not represent "the chimpanzee". Behavioral and Brain Sciences, 33(2-3), 100-101. https://doi.org/10.1017/ S0140525X10000166

Leavens, D. A., Bard, K. A., \& Hopkins, W. D. (2019). The mismeasure of ape social cognition. Animal Cognition, 22(4), 487-504. https://doi. org/10.1007/s10071-017-1119-1

Leavens, D. A., Hopkins, W. D., \& Bard, K. A. (2005). Understanding the point of chimpanzee pointing: Epigenesis and ecological validity. Current Directions in Psychological Science, 14(4), 185-189. https:// doi.org/10.1111/j.0963-7214.2005.00361.x

Leavens, D. A., Russell, J. L., \& Hopkins, W. D. (2005). Intentionality as measured in the persistence and elaboration of communication by chimpanzees (Pan troglodytes). Child Development, 76(1), 291-306. https://doi.org/10.1111/j.1467-8624.2005.00845.x

Leavens, D. A., Russell, J. L., \& Hopkins, W. D. (2010). Multimodal communication by captive chimpanzees (Pan troglodytes). Animal Cognition, 13(1), 33-40. https://doi.org/10.1007/s10071-0090242-z

Liebal, K., Call, J., \& Tomasello, M. (2004). Use of gesture sequences in chimpanzees. American Journal of Primatology, 64(4), 377-396. https://doi.org/10.1002/ajp.20087

MacLarnon, A. M., \& Hewitt, G. P. (1999). The evolution of human speech: The role of enhanced breathing control. American Journal of Physical Anthropology, 109(3), 341-363. https://doi.org/10.1002/(SICl) 1096-8644(199907)109:3\%3C341::AID-AJPA5\%3E3.0.CO;2-2

McCarthy, M. S., Jensvold, M. L. A., \& Fouts, D. H. (2013). Use of gesture sequences in captive chimpanzee (Pan troglodytes) play. Animal Cognition, 16(3), 471-481. https://doi.org/10.1007/s10071-0120587-6

McGrew, W., Ham, R., \& White, L. (1997). Why don't chimpanzees in Gabon crack nuts? International Journal of Primatology, 18(3), 353-374. https://doi.org/10.1023/A:1026382316131

Meguerditchian, A., Molesti, S., \& Vauclair, J. (2011). Right-handedness predominance in 162 baboons (Papio anubis) for gestural communication: Consistency across time and groups. Behavioral Neuroscience, 125(4), 653-660. https://doi.org/10.1037/a0023823

Meguerditchian, A., Vauclair, J., \& Hopkins, W. D. (2010). Captive chimpanzees use their right hand to communicate with each other: Implications for the origin of the cerebral substrate for language. Cortex, 46(1), 40-48. https://doi.org/10.1016/j.cortex.2009.02.013

Meunier, H., Fizet, J., \& Vauclair, J. (2013). Tonkean macaques communicate with their right hand. Brain and Language, 126(2), 181-187. https://doi.org/10.1016/j.bandl.2013.05.004

Micheletta, J., Engelhardt, A., Matthews, L., Agil, M., \& Waller, B. M. (2013). Multicomponent and multimodal lipsmacking in crested macaques (Macaca nigra). American Journal of Primatology, 75(7), 763-773. https://doi.org/10.1002/ajp.22105

Müller, C. (2005). Gestures in human and nonhuman primates: Why we need a comparative view. Gesture, 5(1), 259-283. https://doi.org/ 10.1075/gest.5.1.17mul

Nakamura, M., McGrew, W. C., Marchant, L. F., \& Nishida, T. (2000). Social scratch: Another custom in wild chimpanzees? Primates, 41(3), 237-248. https://doi.org/10.1007/BF02557594

Nishida, T. (1980). The leaf-clipping display: A newly-discovered expressive gesture in wild chimpanzees. Journal of Human Evolution, 9(2), 117-128. https://doi.org/10.1016/0047-2484(80) 90068-8

Partan, S. (2002). Single and multichannel signal composition: Facial expressions and vocalizations of rhesus macaques (Macaca mulatta). Behaviour, 139, 993-1028.

Partan, S., \& Marler, P. (1999). Communication goes multimodal. Science, 83, 1272-1273.

Pika, S., \& Mitani, J. (2006). Referential gestural communication in wild chimpanzees (Pan troglodytes). Current Biology, 16(6), R191-R192. https://doi.org/10.1016/j.cub.2006.02.037

Pinker, S., \& Jackendoff, R. (2005). The faculty of language: What's special about it? Cognition, 95(2), 201-236. https://doi.org/10.1016/j. cognition.2004.08.004

Plooij, F. X. (1978). Some basic traits of language in wild chimpanzees? In A. Lock (Ed.), Action, gestures, and symbol: The emergence of language (pp. 111-132). Academic Press.

Pollick, A. S., \& de Waal, F. B. M. (2007). Ape gestures and language evolution. Proceedings of the National Academy of Sciences of the United States of America, 104(19), 8184-8189.

Prieur, J., Barbu, S., Blois-Heulin, C., \& Lemasson, A. (2020). The origins of gestures and language: History, current advances and proposed 
theories. Biological Reviews, 95(3), 531-554. https://doi.org/10 1111/brv.12576

Prieur, J., Lemasson, A., Barbu, S., \& Blois-Heulin, C. (2018). Challenges facing the study of the evolutionary origins of human righthandedness and language. International Journal of Primatology, 39(2), 183-207. https://doi.org/10.1007/s10764-018-0038-6

Provine, R. R. (1992). Contagious laughter: Laughter is a sufficient stimulus for laughs and smiles. Bulletin of the Psychonomic Society, 30(1), 1-4. https://doi.org/10.3758/BF03330380

Rendall, D., Owren, M. J., \& Ryan, M. J. (2009). What do animal signals mean? Animal Behaviour, 78(2), 233-240. https://doi.org/10.1016/j. anbehav.2009.06.007

Richerson, P. J., \& Boyd, R. (2010). Why possibly language evolved. Biolinguistics, 4(2-3), 289-306.

Rizzolatti, G., \& Arbib, M. A. (1998). Language within our grasp. Trends in Neurosciences, 21(5), 188-194.

Roberts, A. I., Vick, S.-J., \& Buchanan-Smith, H. M. (2012). Usage and comprehension of manual gestures in wild chimpanzees. Animal Behaviour, 84(2), 459-470. https://doi.org/10.1016/j.anbehav. 2012.05.022

Salo, V. C., Rowe, M. L., \& Reeb-Sutherland, B. C. (2018). Exploring infant gesture and joint attention as related constructs and as predictors of later language. Infancy, 23(3), 432-452. https://doi.org/10.1111/ infa.12229

Schamberg, I., Cheney, D. L., Clay, Z., Hohmann, G., \& Seyfarth, R. M. (2016). Call combinations, vocal exchanges and interparty movement in wild bonobos. Animal Behaviour, 122, 109-116. https://doi.org/10.1016/j.anbehav.2016.10.003

Schel, A. M., Townsend, S. W., Machanda, Z., Zuberbühler, K., \& Slocombe, K. E. (2013). Chimpanzee alarm call production meets key criteria for intentionality. PLOS One, 8(10), 76674. https://doi.org/ 10.1371/journal.pone.0076674

Seyfarth, R. M, \& Cheney, D. L (2003a). Meaning and emotion in animal vocalizations. Annals of the New York Academy of Sciences, 1000, 32-55.

Seyfarth, R. M., \& Cheney, D. L. (2003b). Signalers and receivers in animal communication. Annual Review of Psychology, 54(1), 145-173. https://doi.org/10.1146/annurev.psych.54.101601.145121

Slocombe, K. E., Waller, B. M., \& Liebal, K. (2011). The language void: The need for multimodality in primate communication research. Animal Behaviour, 81(5), 919-924. https://doi.org/10.1016/j.anbehav. 2011.02.002

Taglialatela, J. P., Russell, J. L., Schaeffer, J. A., \& Hopkins, W. D. (2011). Chimpanzee vocal signaling points to a multimodal origin of human language. PLOS One, 6(4), 18852. https://doi.org/10.1371/journal. pone.0018852

Tempelmann, S., \& Liebal, K. (2012). Spontaneous use of gesture sequences in orangutans. Developments in Primate Gesture Research, 73-92. https://doi.org/10.1075/gs.6.05tem

Tomasello, M., \& Call, J. (1997). Primate cognition. Oxford University Press.
Tomasello, M., Call, J., Nagell, K., Olguin, R., \& Carpenter, M. (1994). The learning and use of gestural signals by young chimpanzees: A transgenerational study. Primates, 35(2), 137-154.

Tomasello, M., George, B. L., Kruger, A. C., Jeffrey, M., Farrar, \& Evans, A. (1985). The development of gestural communication in young chimpanzees. Journal of Human Evolution, 14(2), 175-186.

Townsend, S. W., Koski, S. E., Byrne, R. W., Slocombe, K. E., Bickel, B., Boeckle, M., Braga Goncalves, I., Burkart, J. M., Flower, T., Gaunet, F., Glock, H. J., Gruber, T., Jansen, D. A. W. A. M., Liebal, K., Linke, A., Miklósi, Á., Moore, R., van Schaik, C. P., Stoll, S., \& Manser, M. B. (2017). Exorcising Grice's ghost: An empirical approach to studying intentional communication in animals: Intentional communication in animals. Biological Reviews, 92(3), 1427-1433. https://doi.org/10.1111/brv.12289

Waller, B. M., Liebal, K., Burrows, A. M., Slocombe, \& Katie, E. (2013). How can a multimodal approach to primate communication help us understand the evolution of communication. Evolutionary Psychology, 11(3), 538-549. https://doi.org/10.1177/147470491301100305

Webster, M. M., \& Rutz, C. (2020). How STRANGE are your study animals? Nature, 582(7812), 337-340. https://doi.org/10.1038/d41586-02001751-5

Wheeler, B. C. (2010). Production and perception of situationally variable alarm calls in wild tufted capuchin monkeys (Cebus apella nigritus). Behavioral Ecology and Sociobiology, 64(6), 989-1000. https://doi. org/10.1007/s00265-010-0914-3

Whiten, A., Goodall, J., McGrew, W. C., Nishida, T., Reynolds, V., Sugiyama, Y., Tutin, C. E. G., Wrangham, R. W., \& Boesch, C. (1999). Cultures in chimpanzees. Nature, 399(6737), 682-685. https://doi.org/10.1038/ 21415

Wilke, C., Kavanagh, E., Donnellan, E., Waller, B. M., Machanda, Z. P., \& Slocombe, K. E. (2017). Production of and responses to unimodal and multimodal signals in wild chimpanzees, Pan troglodytes schweinfurthii. Animal Behaviour, 123, 305-316. https://doi.org/10.1016/j.anbehav. 2016.10.024

\section{SUPPORTING INFORMATION}

Additional Supporting Information may be found online in the supporting information tab for this article.

How to cite this article: Rodrigues, E. D., Santos, A. J., Veppo, F., Pereira, J., \& Hobaiter, C. (2021). Connecting primate gesture to the evolutionary roots of language: A systematic review. Am J Primatol, 83, e23313.

https://doi.org/10.1002/ajp.23313 